sity of London that both taxonomy and the more practical side of entomology were subjects worthy of study at university level. Moreover, by developing during his career two different field stations, he showed the important part such institutions can play in university teaching, at least in subjects such as entomology.

Munro took his degree in zoology at the University of Edinburgh and then studied forestry at Aberdeen and at Tharandt, in Germany, under Escherich. Soon after his return to England his career was interrupted by the First World War and after a period of service in France he was withdrawn to work at Cambridge with Nuttall and Bacot on the problems of lice and scabies. About the latter, in particular, he made a valuable discoverynamely, that the main centre of itching was some distance away from the area where the mites were most numerous.

After the war, he returned to forestry. The Forestry Commission had just been set up to remedy a national deficiency which the war had brought to light. Munro wrote to the Commission proposing a programme of forest entomology which to a large extent it adopted, employing him to put it into effect. This gave him not only $a$ wide knowledge of practical problems all over Britain but also taught him some lessons in dealing with administrators and government servants. Part of his work was done at Kew and here he met the late Sir John Fryer and formed a friendship which was later fruitful when Fryer was at the Ministry of Agriculture and the Agricultural Research Council (ARC).

Munro devised the first entomological programme for the Forest Products Research Laboratory and his career in the subject seemed well launched when he was appointed to the Imperial Forestry Institute at Oxford. However, the subject did not develop there as he had hoped and he soon transferred to the Imperial College as assistant professor of entomology. Here he not only resuscitated what was a moribund department but as a substitute for the forests began the study of insect pests of stored foods in the London docks. Some of the insects could best be controlled by fumigation with various gases, but experi. ments with these were difficult to do in South Kensington. Munro was able to obtain a grant from the Empire Marketing Board to set up a field station at Slough where such experiments were possible. These experiments not only led to the development of a scientific basis for the whole subject of fumigation, previously entirely empirical and often ineffective, but also enabled a revolution to be made in the teaching of entomology at the college, with a much greater emphasis on field work and on the study of the live insect.

The work on "stored products insects" continued up to 1939 and, just before the outbreak of the Second World War, Munro had persuaded the Department of Scientific and Industrial Research (DSIR) that there was a serious practical problem which fell within its province. A system of inspection, backed by laboratory research, was set up and later taken over by the Ministry of Food and the DSIR, Munro becoming their consultant. However, in the latter part of the war he became interested in problems of medical entomology, particularly the practical control of malaria-carrying mosquitoes in jungle warfare.

In 1930 Munro had been appointed professor of entomology at Imperial College, and in 1934, when MacBride retired, the zoology and entomology departments were combined and he was appointed professor of zoology and applied entomology. After the war the college field station remained in the hands of the DSIR (now of the ARC) and Munro had not only to build up a very depleted department but to find a new field station, at a time when it was difficult to get building licences. $\mathrm{He}$ found a suitable site and a building capable of adaptation at Silwood Park, near Ascot, and, until his retirement in 1953, most of his energies, so far as he was not doing valuable work on a number of official committees, were devoted to developing Silwood so that the very necessary liaison between applied entomology and ecology would find an ideal site. Munro was prepared to examine any problem from every side and call on more than one scientific discipline, but he had an uncanny knack of finding out the most rewarding approach and, after the initial survey, concentrating on the sort of work which was most needed. It was this that made him a great and successful entomologist.

\section{Professor L. Infeld}

Lwopold INFELd died on January 15, 1968, in Warsaw. With his death, Poland lost her most distinguished theoretical physicist and the world lost a courageous and wise man.

Infeld was born in Cracow on August 20, 1898. $\mathrm{He}$ attended school there and later the Jagiellonian University where he received his doctorate in 1921. After several years of high school teaching, he worked at the University of Lwow from 1929 to 1936 . During a short visit to Leipzig, Infeld and van der Waerden wrote an important paper on the generalization of the spinor ealculus and of Dirac's equation to general relativity theory. In 1934, Infeld was awarded a Rockefeller Fellowship to work at the University of Cambridge. There he collaborated with Max Born on what is now known as the Born--Infeld theory. It was an attempt to explain the existence of elementary charged particles in terms of well behaved solutions of non-linear equations for the electromagnetic field.

In 1936 Infeld accepted a research appointment at the Institute for Advanced Study in Princeton. He worked with Albert Einstein and Banesh Hoffmann on the equations of motion in general relativity, a problem which occupied his main research interest for the rest of his life. The work showed that Einstein's theory of gravitation has a unique feature, that the field laws alone determine the motion of particles and that no independent laws of motion are needed. This beautiful result is intimately connected with the non-linearity of the gravitational field equations. It should play an important part in the future development of the whole of theoretical physics. The work also gave the first satisfactory description of the motion of several particles in gravitational interaction, such as the relativistic motion of a double star. In 1960 , Infeld and his former student Jerzy Plebanski published a treatise on motion and relativity.

After two years at Princeton, Infeld accepted a professorship in the University of Toronto where he stayed until 1950. At that time he returned to Warsaw and established a new research centre in theoretical physics. Many of his Canadian and Polish research students now have professorships at universities on the North American continent and in Poland. He received many scientific honours. He was elected to the Royal Society of Canada and to the scientific academies of Poland, Hungary and Berlin. Since 1953, he has been a member of the Presidium of the Polish Academy of Sciences.

Infeld was the author of several books. With Albert Einstein he wrote The Evolution of Physics, an exposition of modern scientific ideas for the layman. He also wrote a book on Einstein, two autobiographical volumes and a novel on the life of Evariste Galois.

Leopold Infeld was a remarkable man. He had a great zest for life and a great concern for human beings. He believed that intellectuals should speak out on human conditions and he always did so himself, with a simple elarity which was convincing and effective. $\mathrm{He}$ was particularly concerned with the great danger of our age, the annihilation of life on our planet by nuclear weapons. He was one of the original signatories of the EinsteinRussell letter of 1955. He helped organize the Pugwash conferences which brought together scientists from the East and West. 